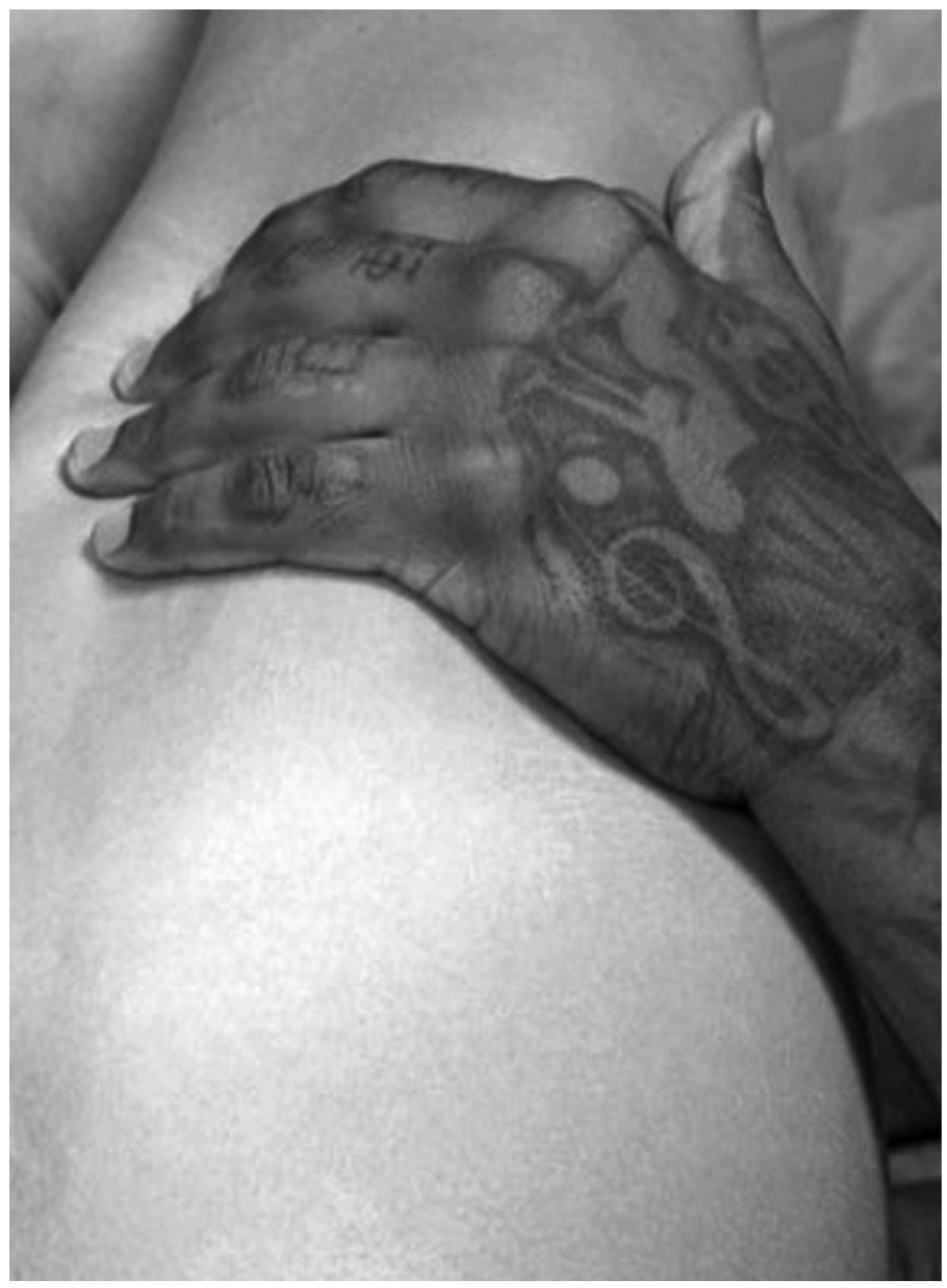




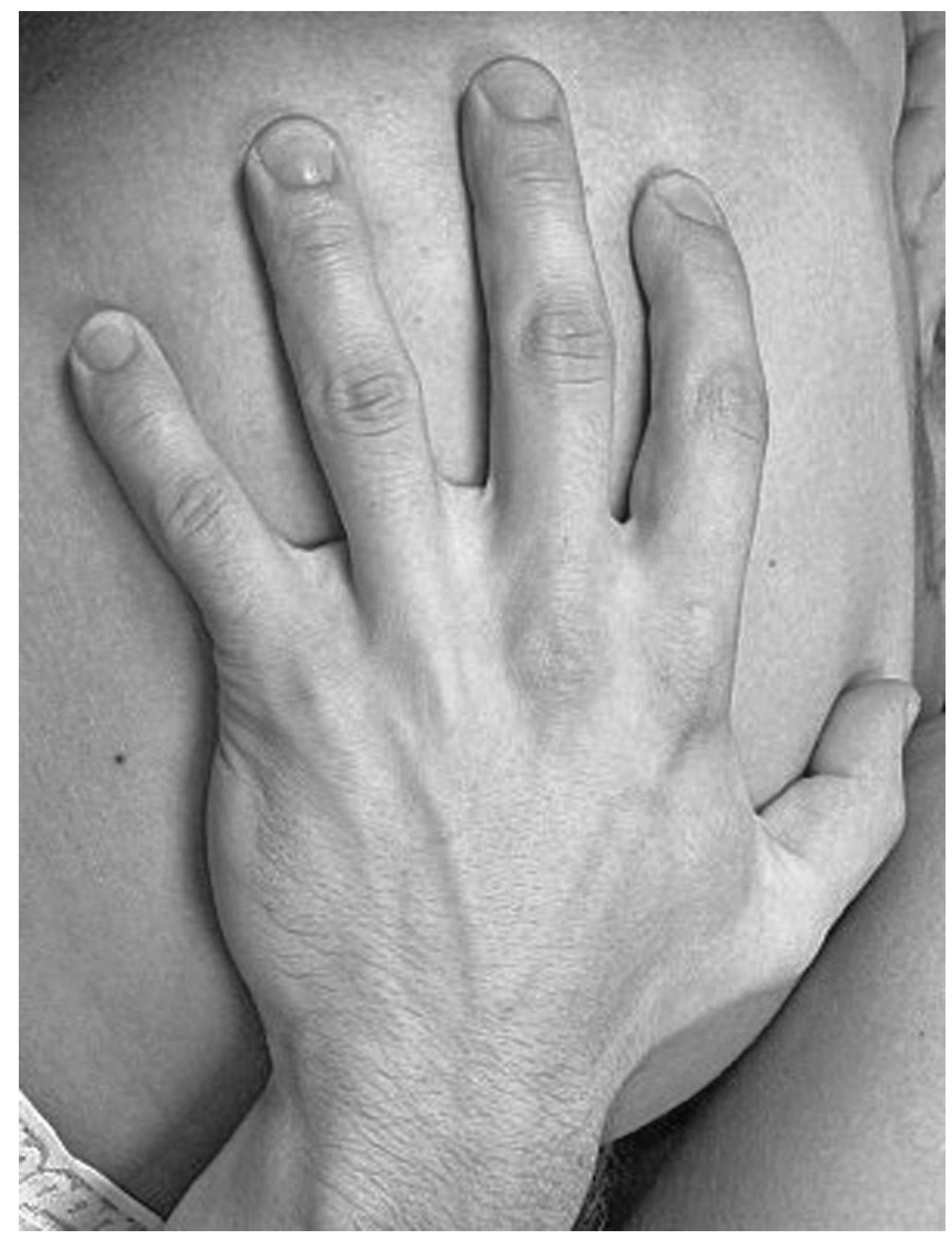




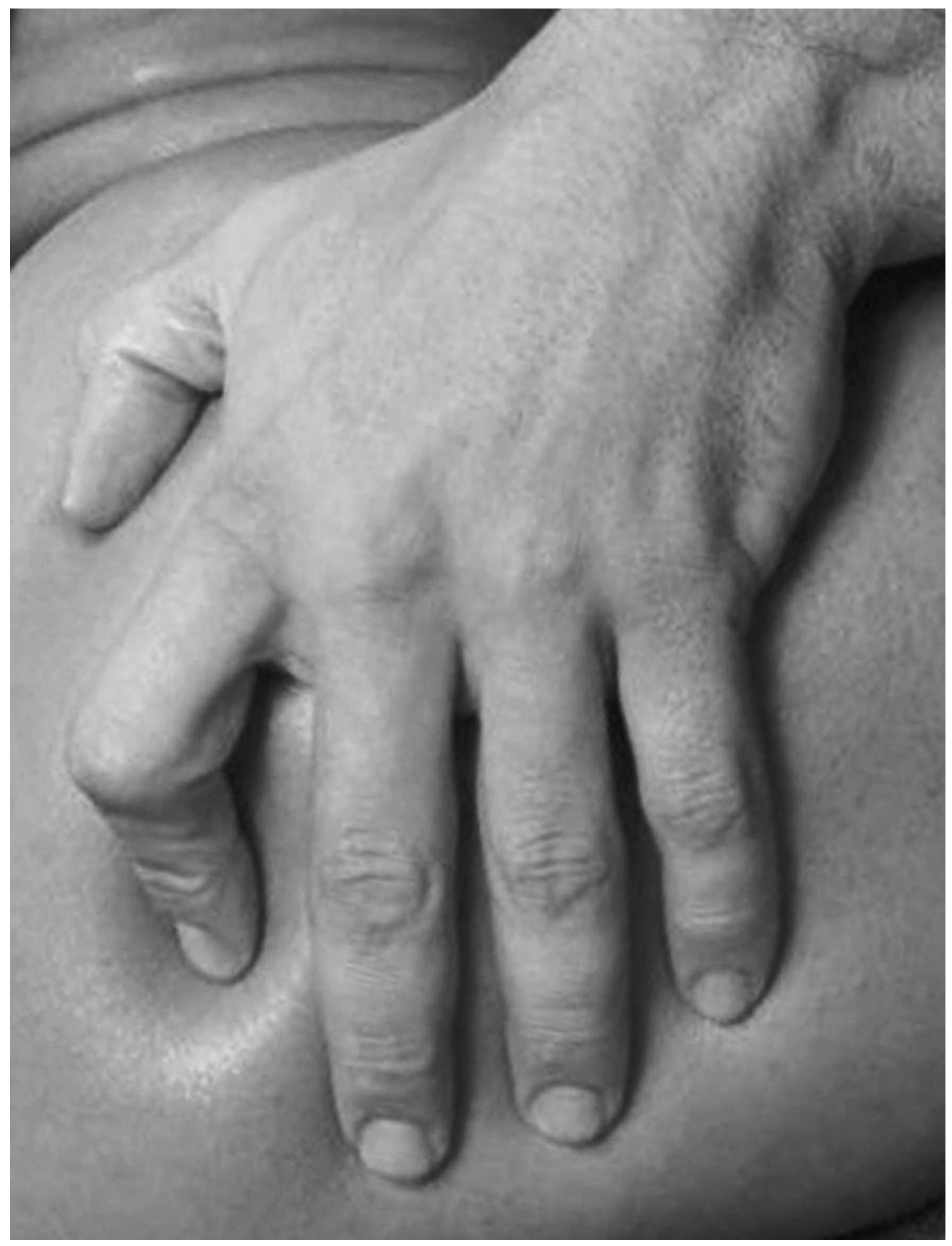




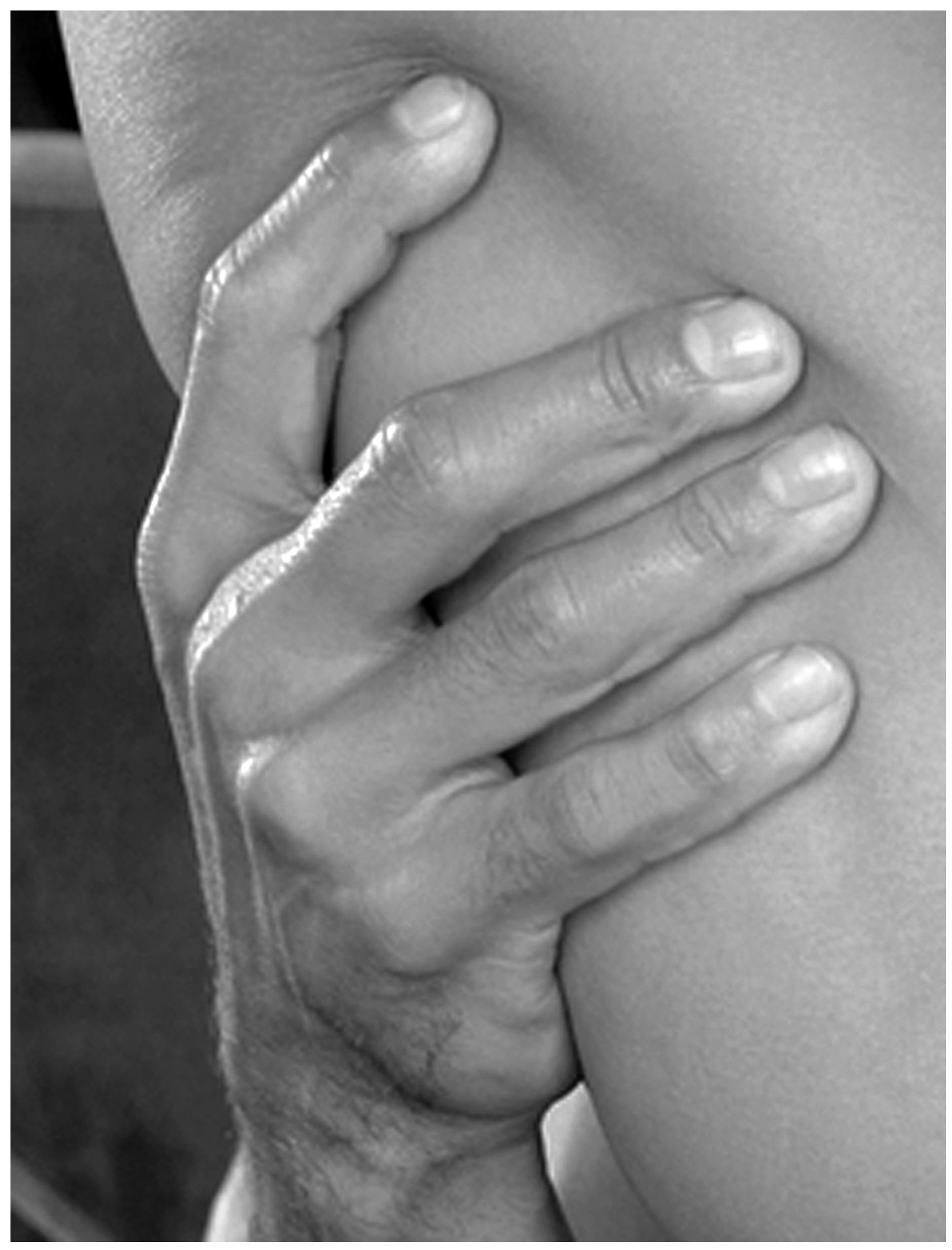




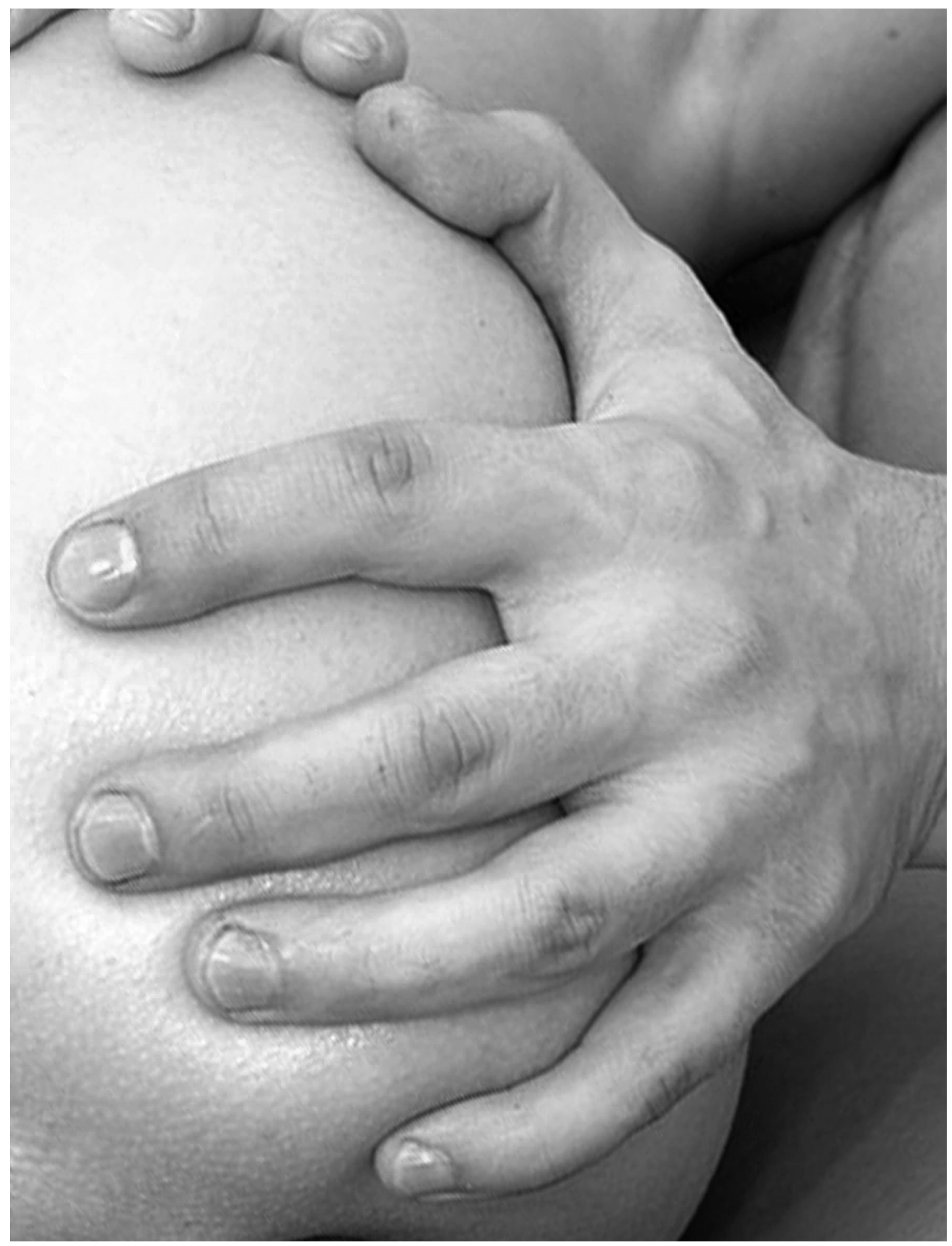




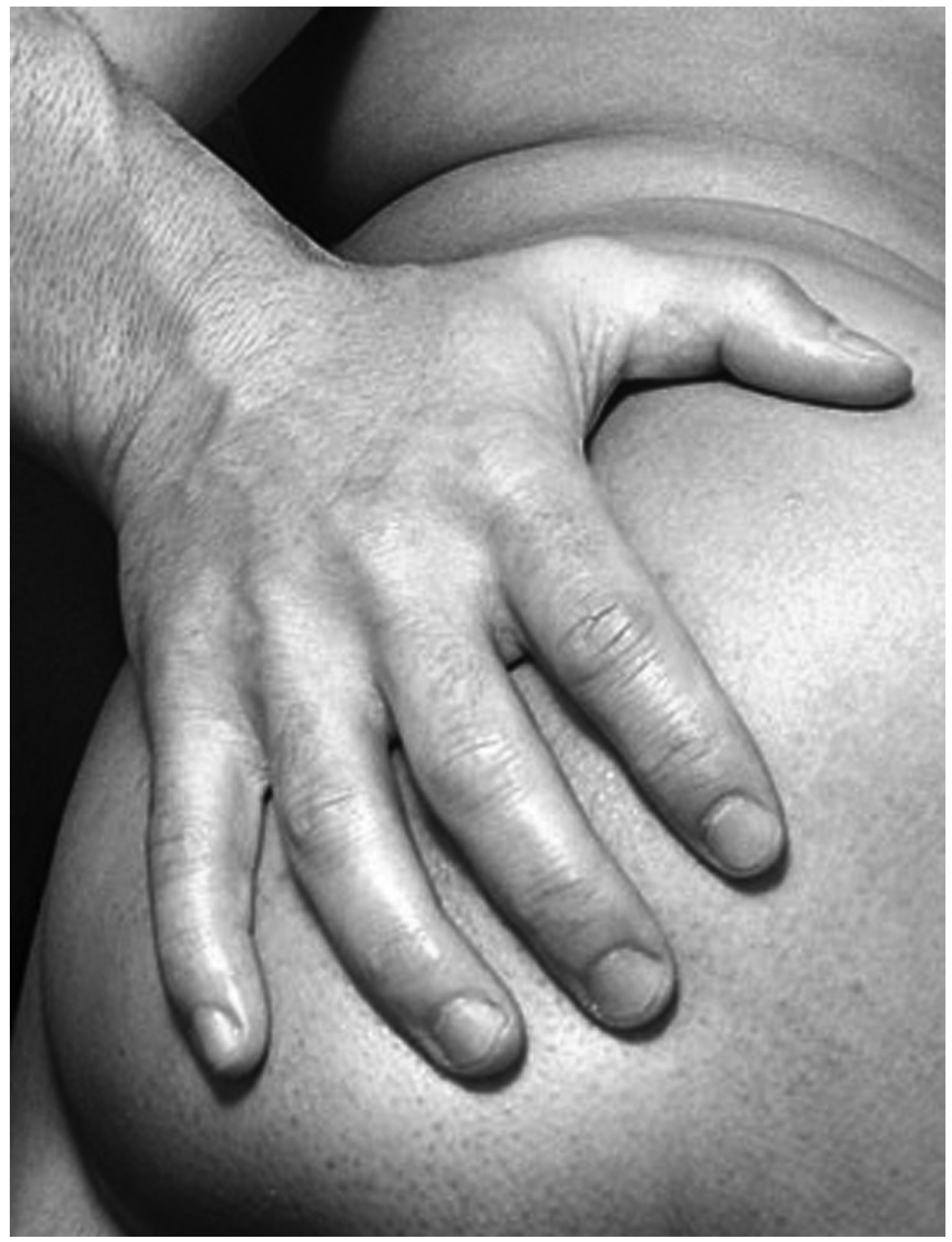




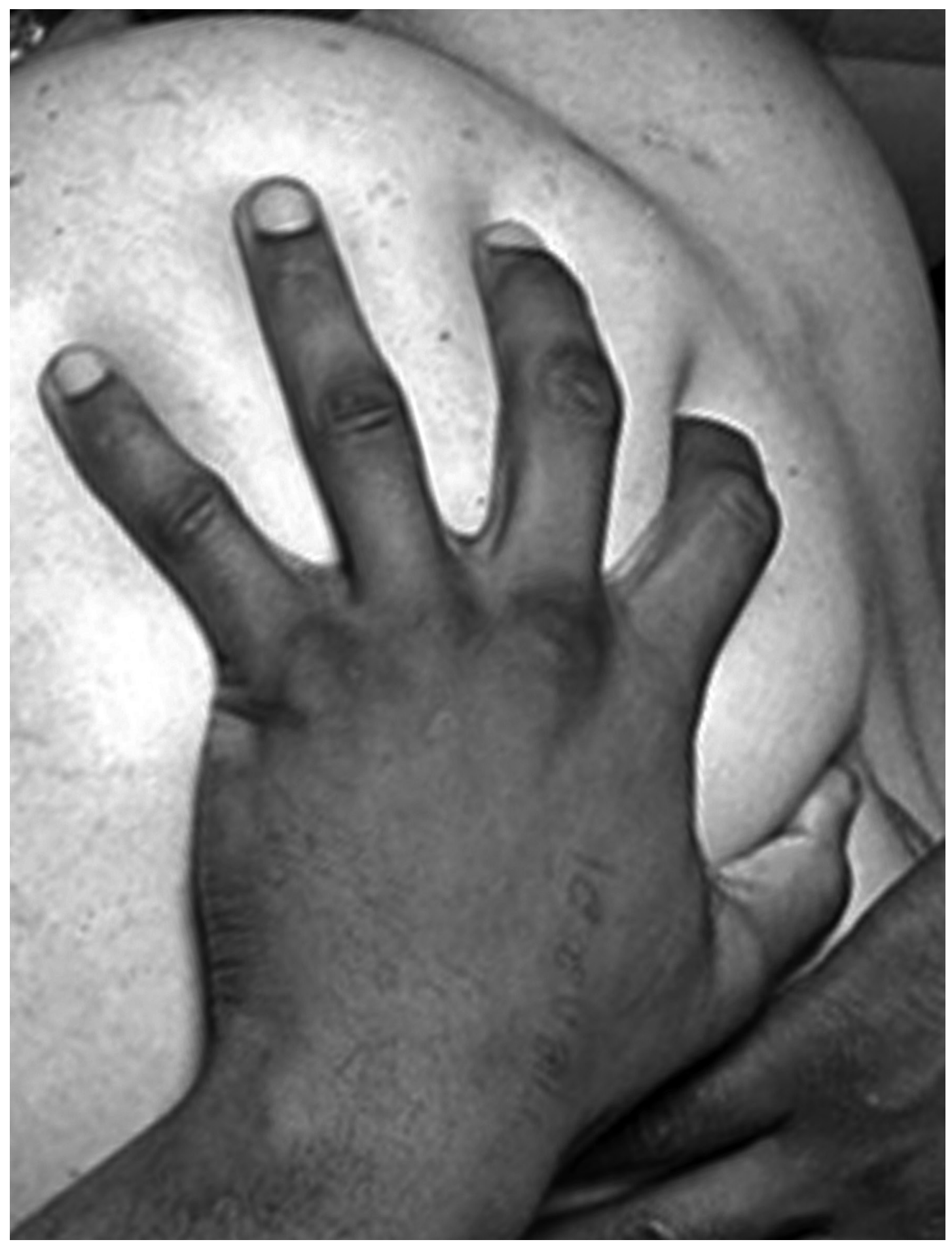




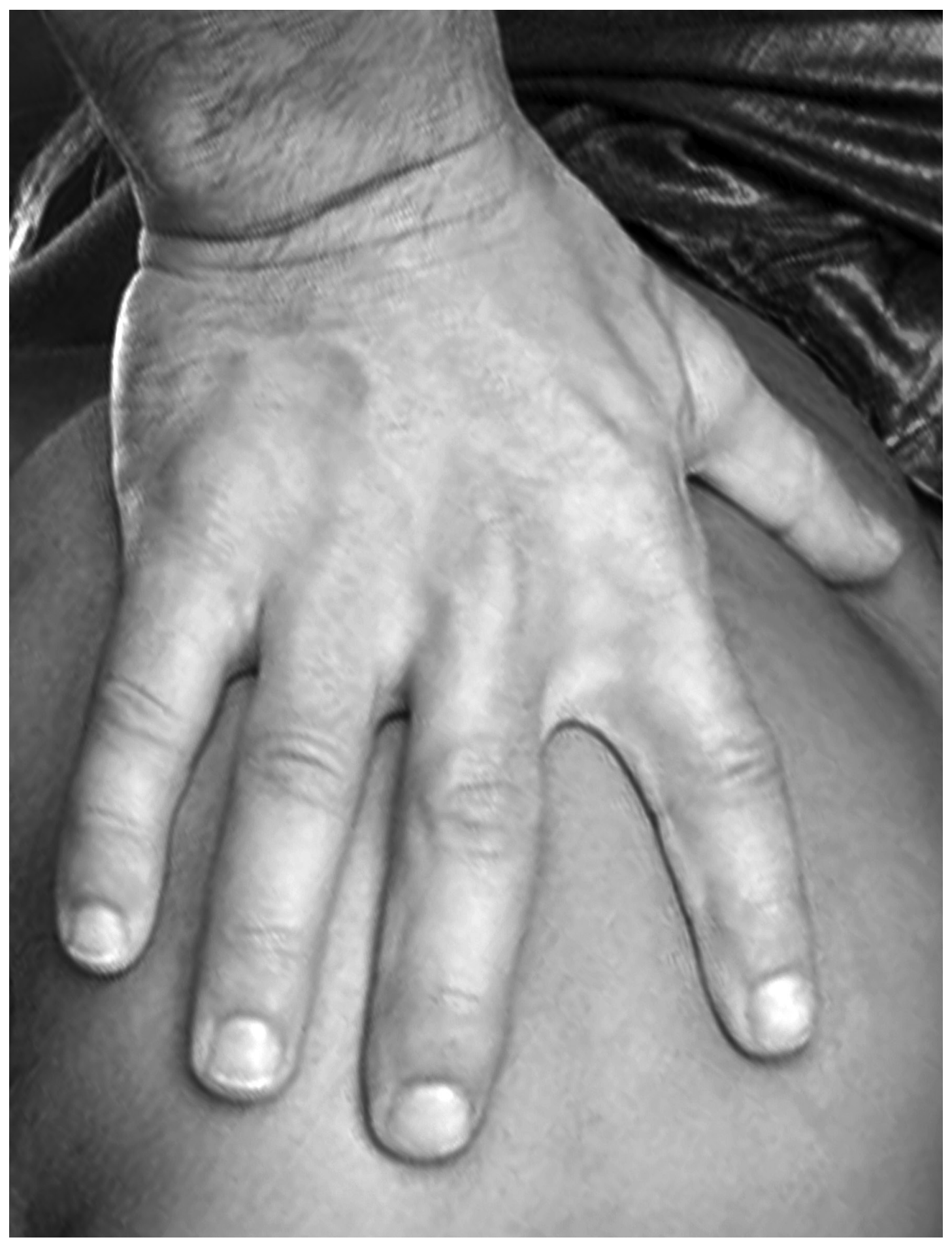




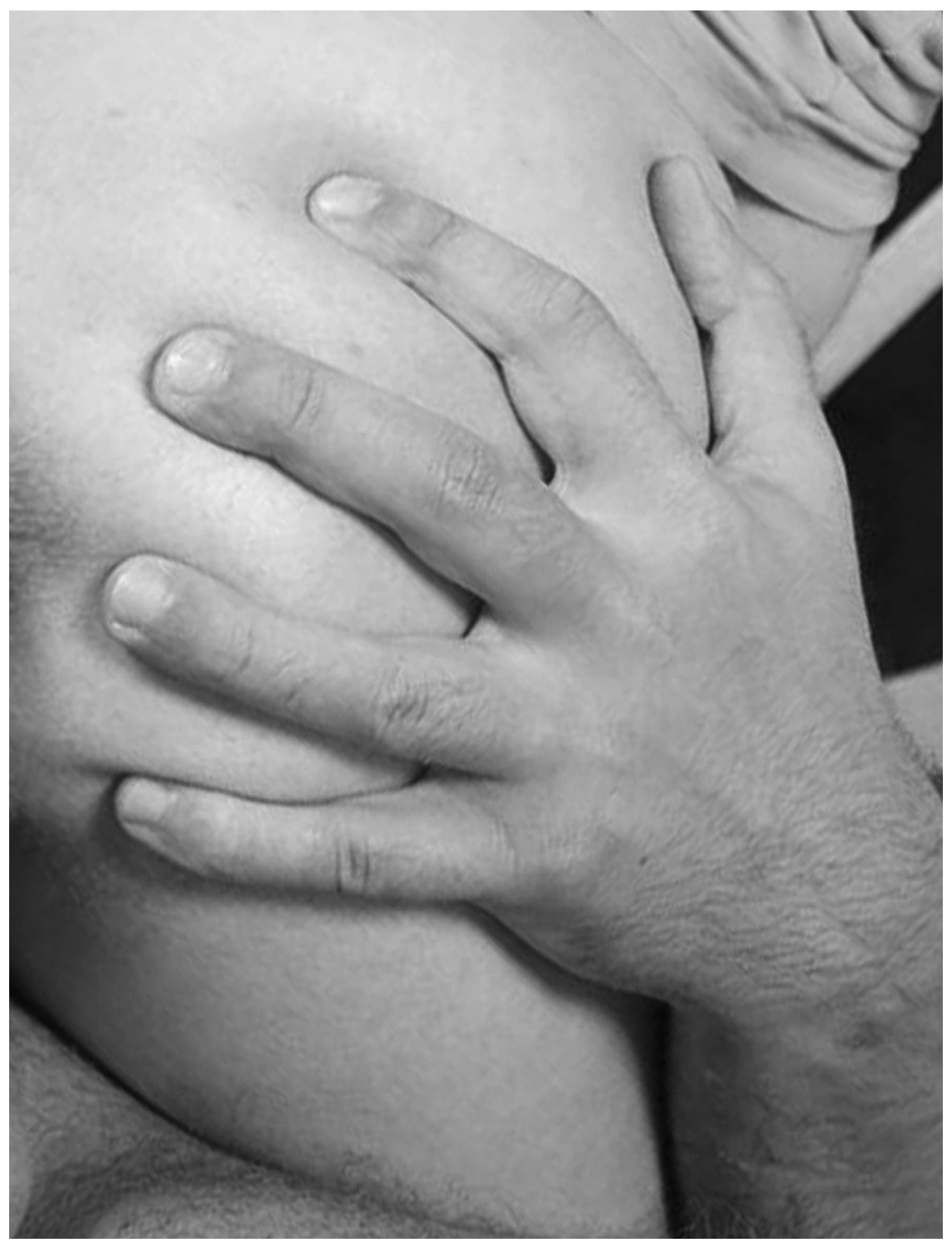




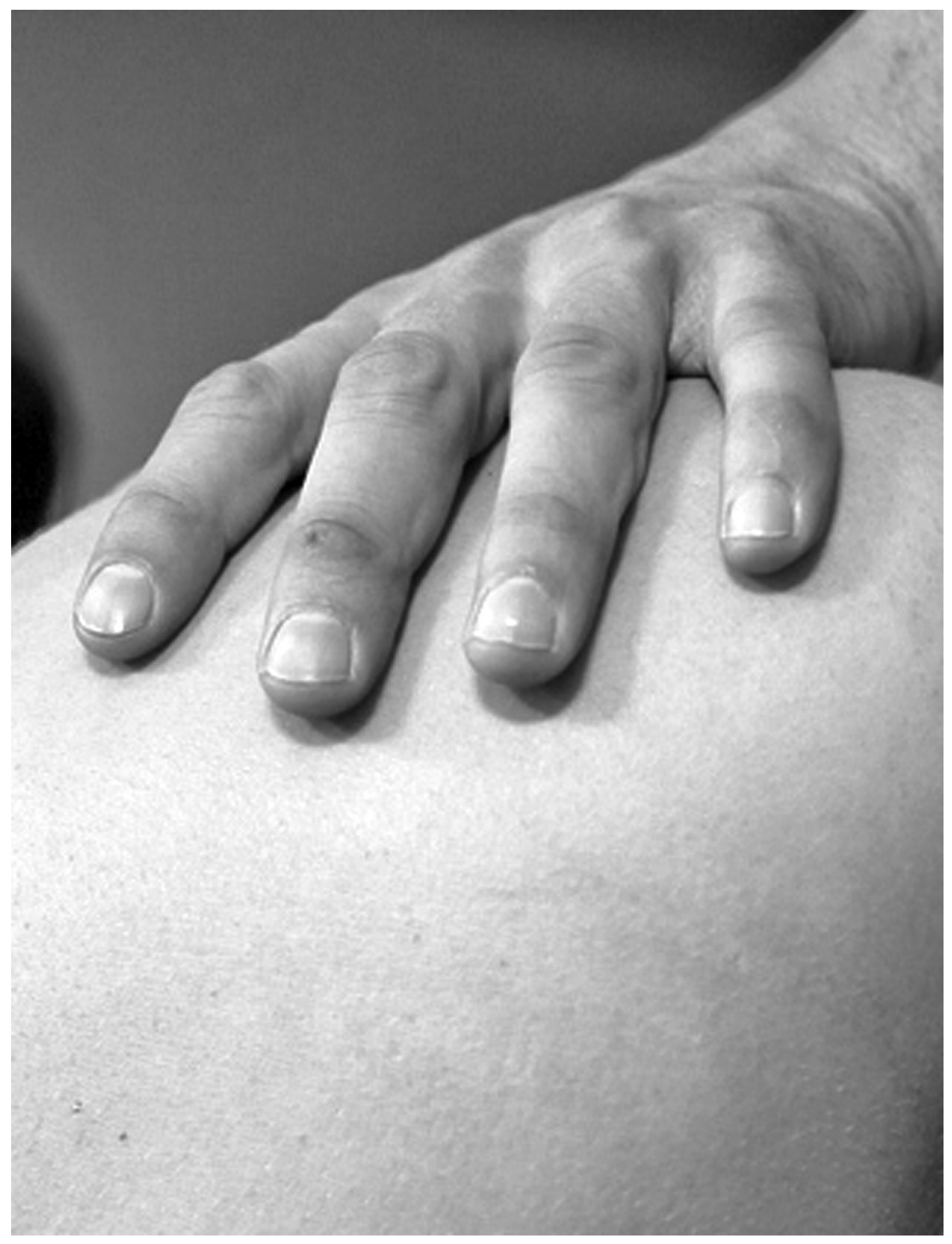




\section{Mario Ramiro}

Rapto das Sabinas (handbook) 